\title{
RADAR-BASED RAINFALL ESTIMATION IN BOYONG RIVER (BO-D5)
}

\author{
Henggar Risa Destania ${ }^{1 *}$, AChMad Syarifudin ${ }^{2}$ \\ ${ }^{l}$ Civil Engineering Faculty, Universitas Indo Global Mandiri, Jl. Jend. Sudirman no. 629, South \\ Sumatera, Indonesia \\ ${ }^{2}$ Civil Engineering Faculty, Universitas Bina Darma, Jl. Jend. A.Yani No. 12, South Sumatera, \\ Indonesia \\ *Corresponding author: henggarrisa@ uigm.ac.id
}

(Received: 15 September 2021; Accepted: 14 November 2021; Published on-line: 1 March 2022)

\begin{abstract}
Sediment-related disasters are terrible disasters that can catastrophically impact facilities. People must keep in mind to make sediment-related disaster information that can be predicted from rainfall and response of drainage area by using snakelike. This research produces important indices on precipitation related to debris. It shows the current status of the stage of the response of drainage area against rainfall by using a couple of short- and longterm indices. It shows the water storage volume in the soil layer with the calculation of soil water index (SWI) by using X-band MP (Multi-Parameter) rainfall radar data that has been installed at the top of Merapi Mountain (Merapi Museum). It was confirmed that from June 2018 - June 2019, with $80.28 \mathrm{~mm} \mathrm{SWI}$, maximum values do not exceed the standard reference value of SWI $(120-160 \mathrm{~mm})$ set from JMA. It means that $80.28 \mathrm{~mm}$ of SWI value has not yet become the maximum limit of SWI value for lahar occurrence in the Boyong drainage area (BO-D5). The maximum limit of SWI value can be generated if sediment disaster occurrences are available.
\end{abstract}

KEYWORDS: Radar-Based, Rainfall, Boyong River

\section{INTRODUCTION}

Sediment-related disasters are terrible disasters that can catastrophically impact facilities. People must keep in mind to make sediment-related disaster information that can be predicted from rainfall and response of drainage areas. However, since sediment-related disasters are greatly affected by the degree of vegetation, geology, weathering and groundwater conditions, it is impossible to specify individual disaster occurrence places, time, scale, etc.

Sediment-related disaster information, whether sediment-related disaster risk is high or low, could be informed in real-time based on rainfall indices using X-band MP (MultiParameter) rainfall radar. This system facilities a sophisticated measurement based on rainfall intensity (calculated using the distribution of precipitations and the polarisation phase difference) and is more sensitive to rain attenuation phenomena. This sediment disaster claimed many victims, so it is necessary to provide technical and system support for future information provision.

The data from X-band MP (Multi-Parameter) rainfall radar will provide information of rainfall intensity in the form of a more proportional grid so the area of rain whose value will be different from that will not exposed to rain. Rain data derived from X-band MP rainfall radar estimates in graphical formats with colour differences for higher intensity areas. In this way, the rainfall over the drainage area can be better represented. X-band MP rainfall radar has a 
higher spatial resolution. It is suitable for the mountainous area due to its small size and weight, so mean regional rainfall can also be better predicted because the movement and development of rain can be continuously monitored by scanning.

This research produces important indices on precipitation related to sediment disasters. It shows the current status of the stage of the response of drainage area against rainfall by using a couple of short and long term indices as a rainfall estimation.

The water storage volume in the soil layer with the calculation of soil-water index using a tank model by using X-band MP (Multi-Parameter) rainfall radar data that has been installed at the top of Mount Merapi (Merapi Museum) Yogyakarta in 2015.

This research aims to analyse the fluctuation of time series and spatial distribution using X-band MP (Multi-Parameter) rainfall radar. In addition, the purpose of this is to understand current stage response information of drainage area against rainfall by using short and long term rainfall based on several rainfall indices (2-min rainfall intensity and soil-water index) and X-band MP (Multi-Parameter) rainfall radar data in the upstream of Boyong river at Mount Merapi. The combination of setting rainfall indices and X-band MP (Multi-Parameter) rainfall radar data is more scientific precision of timing and location. Rain attenuation phenomena and monitoring spatial distribution of rainfall can be useful to identify current stages of the drainage area and rainfall characteristics to make sediment-related disaster information.

\section{SOIL WATER INDEX USING TANK MODEL}

Osanai et al. [1] state that prevention works that include structural and non-structural measures against sediment disasters related to mass movement define the types of mass movement as (1) debris flows, (2) slope failures, (3) landslides in a limited sense (deep-seated landslides). The tank model is a hydrological model usually used to calculate water discharge and amount in the near-surface soil layers and estimate the total rainwater in soil from the rainfall data [2].

MSD/SSDM (Support System of Decision Making) is a giant database that contains information and data that can be used to run the simulator and create information needed regarding disaster prevention measures. It has been developed to help the user mitigate various volcanic disasters, including pyroclastic flow, lahar and ash dispersion. MSD/SSDM was conducted in a series of SATREPS (Science and Technology Research Partnership for Sustainable Development) programs to join cooperative research involving government and higher educational institutions between Japan and Indonesia [3].

Saito et al. [4], [5] defined SWI as a concept model that uses a calculated value of the total water depth of a three-layer tank model estimated using fixed parameters in Japan. Soil water index (SWI) is the total storage amount remaining in each tank. This corresponds to the amount of moisture in the soil. As it rains, rainfall will flow on the surface, flow into the river and soak into the ground. The tank model indicates the precipitation and evaporation process into the tank-layer model.

The soil water index, hereinafter called SWI, is one of the rainfall indices that has been used for early warning systems operated by the Ministry of Land, Infrastructure, Transport and Tourism (MLIT) and the Japan Meteorological Agency (JMA). Saito et al. [5] studied Japanese early warning for debris flows and slope failures using several rainfall indices (60-min cumulative rainfall and soil water index). They set the criterion for early warning issues by using the Radial Basis Function Network (RFBN) and introducing the new Japanese early warning system for disaster risk reduction. 
Another research about soil water index is from Chen et al. [2] about soil water index applied as a debris flow warning reference based on a tank model in Eastern Taiwan. They analysed the debris flows cases in Eastern Taiwan based on the tank model and the current warning threshold value for debris flow. The results showed SWI has a linear relationship with depth in the second tank, i.e. the soil moisture in the middle soil layer is closely related to debris flow cases. In Eastern Taiwan, debris flow occurred when SWI > $107 \mathrm{~mm}$ and can be used as a disaster warning in Eastern Taiwan.

\section{RESEARCH METHOD}

\subsection{Research Location}

This research is conducted in Boyong River around Mount Merapi, as shown in Fig.1. Xband MP radar (Multiparameter Polarimetric Radar) is used for monitoring rainfalls produced by Furuno Japan with WR-2100 model and have been installed in the top of Merapi Museum with a fixed observation area was set within $30 \mathrm{~km}$.

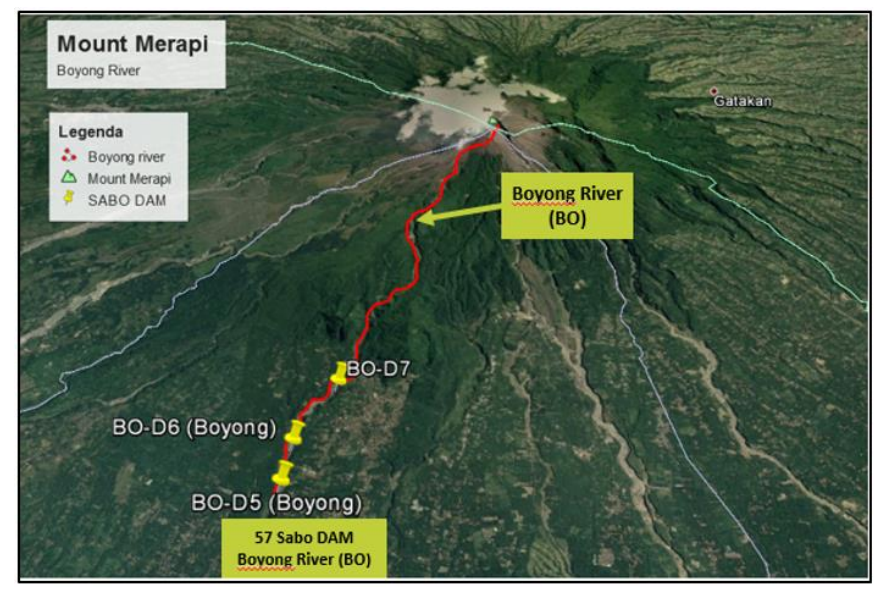

Fig. 1. River flow of Boyong River with SABO DAM from google earth.

\subsection{Structure Component for Extracting Event Chain}

In this research analysis, structure components for extracting event chain were conducted to simplify understanding and analysing rainfall patterns and disaster chain response to the drainage area. Its structure is shown in Fig. 2.

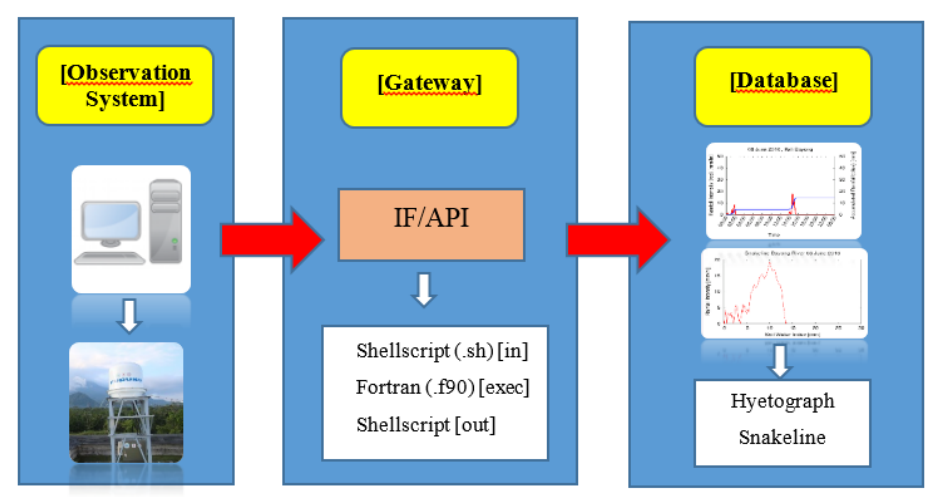

Fig. 2. Structure component for extracting data. 


\subsection{Research Flowchart}

The flowchart of this research can be seen in Fig. 3 .

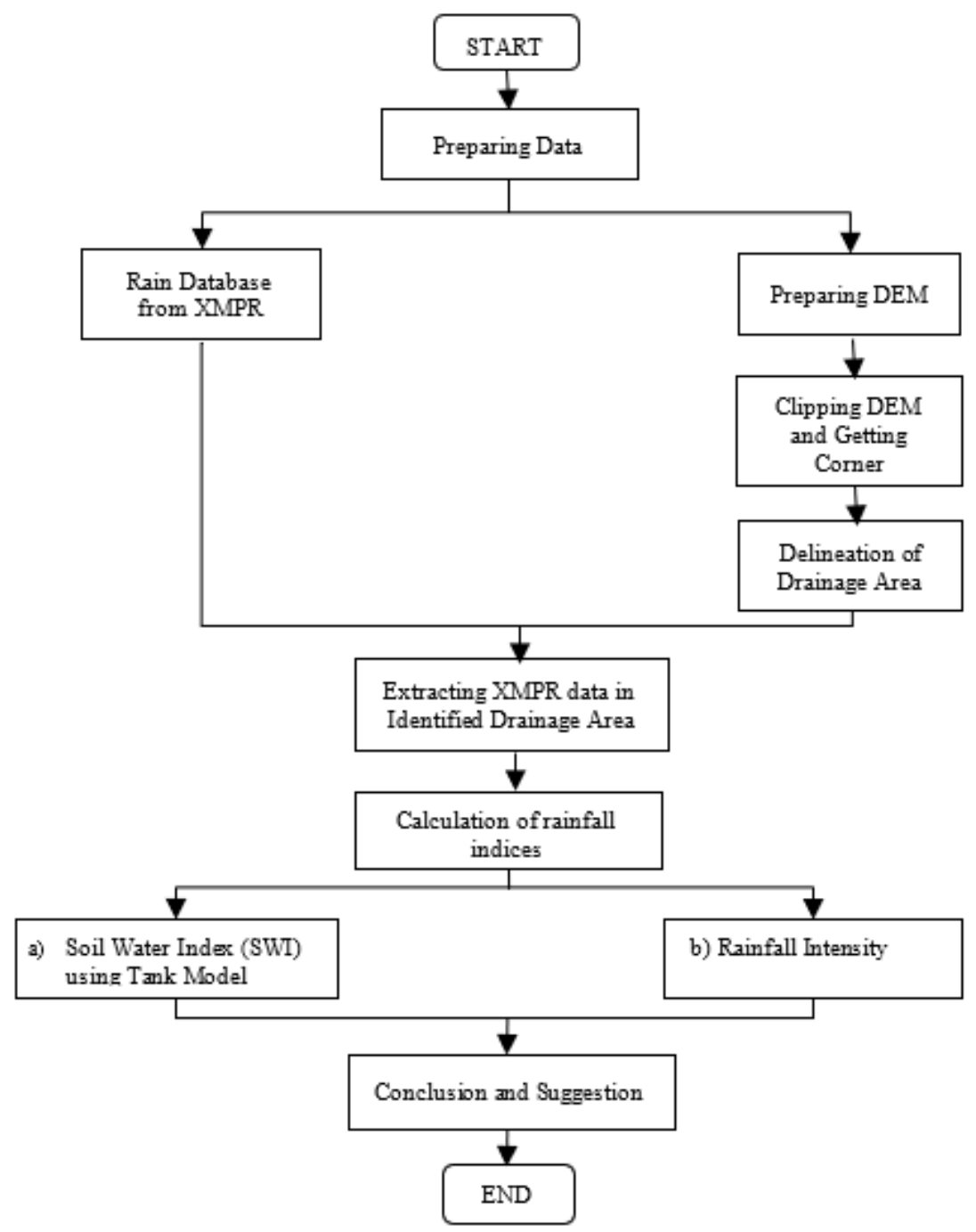

Fig. 3. Research flowchart.

\subsection{Data Collections}

This research uses some data supporting for conducting analysis of snakeline for this research as shown in Table1.

Table 1: Data requirement

\begin{tabular}{|c|c|c|c|c|}
\hline No & Data Type & Details & Purpose & Source \\
\hline 1. & Rainfall data (spatial) & $\begin{array}{l}\text { Continous rainfall every } 2 \\
\text { minutes from June } 2018- \\
\text { June } 2019 \text { ( } 1 \text { year) }\end{array}$ & $\begin{array}{l}\text { Rainfall } \\
\text { Characteristics }\end{array}$ & X-Band MP rainfall radar \\
\hline & DEM & $\begin{array}{l}\text { SRTM }(\mathbf{3 0} \mathbf{~ m}) \\
-\quad 30 \mathrm{~m} \text { resolution } \\
\text { ASTGTM2 }(\mathbf{3 0} \mathbf{~ m}) \\
-\quad 30 \mathrm{~m} \text { resolution } \\
\text { ALOS3WD }(\mathbf{5} \mathbf{~ m}) \\
-\quad 10 \mathrm{~m} \text { and } 15 \mathrm{~m} \\
\quad \text { resolution } \\
\end{array}$ & $\begin{array}{ll}- & \begin{array}{l}\text { Determination } \\
\text { of watershed }\end{array} \\
\text { - } & \text { Delineation of } \\
& \text { watershed }\end{array}$ & $\begin{array}{ll}\text { - } & \text { https://gdex.cr.usgs.go } \\
\text { v/gdex/ (open source) } \\
\text { - } & \text { SATREPS (Tsukuba } \\
\text { server) }\end{array}$ \\
\hline
\end{tabular}




\subsection{Utilisation of X-Band Rainfall Radar}

The utilisation of X-Band MP Radar for identifying drainage areas and extracting XMPR data is in the following file system in Figure 4. This research was conducted with system requirements such as Tsukuba server system are using Ubuntu OS (open source and free OS). The researcher uses remote desktops such as PuTTY and VNC to access the MSD/SSDM server by Windows OS, Interfaces/Application Program Interface (IF/API) was made to support making input and output datasets. The IF/API was coded using shell script (bash) and FORTRAN based on a UNIX system. This program is one of the file transferring client software used to download files from the SSDM server directly transferred into a PC to run a certain program. Certain programs on the server cannot operate if using remote access like PuTTY and VNC. The scripts of the FORTRAN can be seen in Fig. 4.

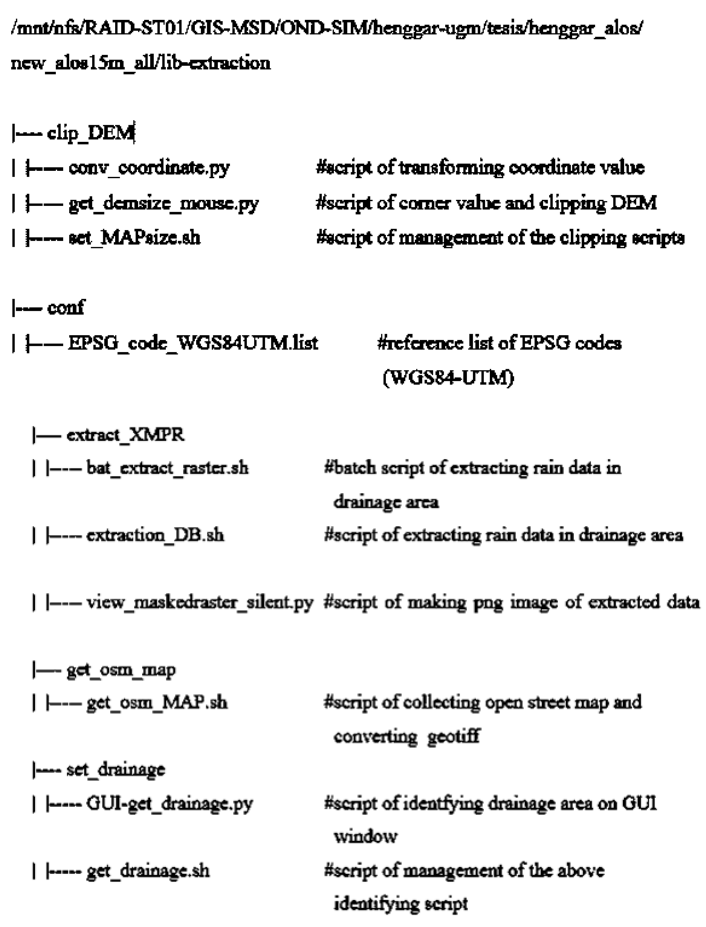

Fig. 4. Several scripts for extracting data.

\subsection{Soil Water Index (SWI) using Tank Model}

Soil water index (SWI) is the total storage amount remaining in each tank. This corresponds to the amount of moisture in the soil. As it rains, rainfall will flow on the surface, flow into the river and soak into the ground. The tank model indicates the precipitation and evaporation process into the tank-layer model. Outflow holes indicate the water flows out to the surrounding soil on the side of each tank. The amount of outflow from the side hole outflow in the first tank corresponds to the surface runoff, one of the second tank corresponds to the infiltration. The inflow into the first tank corresponds to rainfall, the inflow into the second tank flows out through the infiltration outflow hole of the first tank, and the inflow into the third tank flows out from the infiltration outflow hole from the second tank, as shown in Fig. 5. Table 2 is the SWI parameter that was used in this study. 


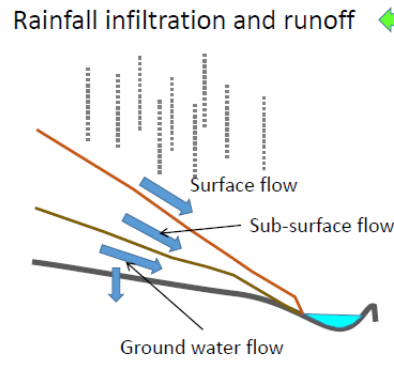

Ground water flow

Water storage volume

in soil layer

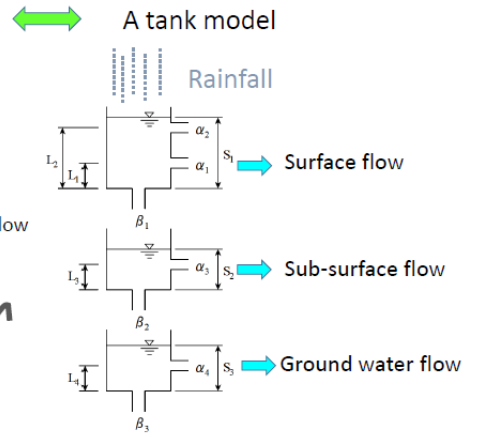

Soil water index $\mathrm{S}_{1}+\mathrm{S}_{2}+\mathrm{S}_{3}$

Fig. 5. Concept of SWI using tank model and SWI parameter.

Table 2: SWI Parameters

\begin{tabular}{lccc}
\hline \multicolumn{1}{c}{ Tank Layer } & Outflow Height $(\mathbf{m m})$ & Outflow coefficient $(\mathbf{1} / \mathbf{h})$ & $\begin{array}{c}\text { Coefficient of } \\
\text { Permeability }(\mathbf{1} / \mathbf{h})\end{array}$ \\
\hline First tank & $\mathrm{L}_{1}=15$ & $\alpha_{1}=0.1$ & $\beta_{1}=0.12$ \\
& $\mathrm{~L}_{2}=60$ & $\alpha_{2}=0.15$ & \\
Second tank & $\mathrm{L}_{3}=15$ & $\alpha_{3}=0.05$ & $\beta_{2}=0.05$ \\
Third tank & $\mathrm{L}_{4}=15$ & $\alpha_{4}=0.01$ & $\beta_{3}=0.01$ \\
\hline
\end{tabular}

\section{RESULTS}

\subsection{Getting Corner Coordinate and Clipping DEM}

Clipping DEM was conducted to minimise location area for research due to the running time of extracting rainfall by using the command as shown in Fig. 6.

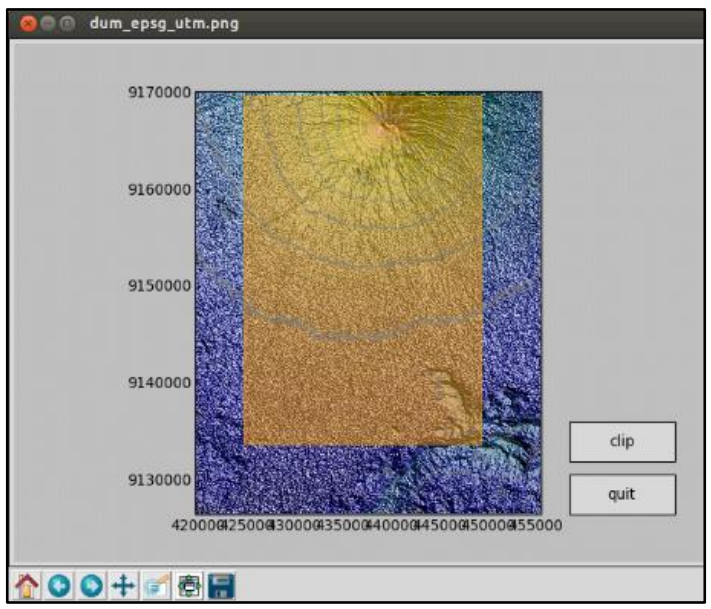

Fig. 6. Image of GUI window on the process of clipping DEM in Boyong river (BOD5). 


\subsection{Delineation of Drainage Area}

Delineation of drainage area was conducted using command to execute and get drainage area as ESRI shape and geotiff files with outlet point's coordinate (BO-D5), which is already defined using the terminal window as shown in the concept of getting drainage area in Fig. 7.

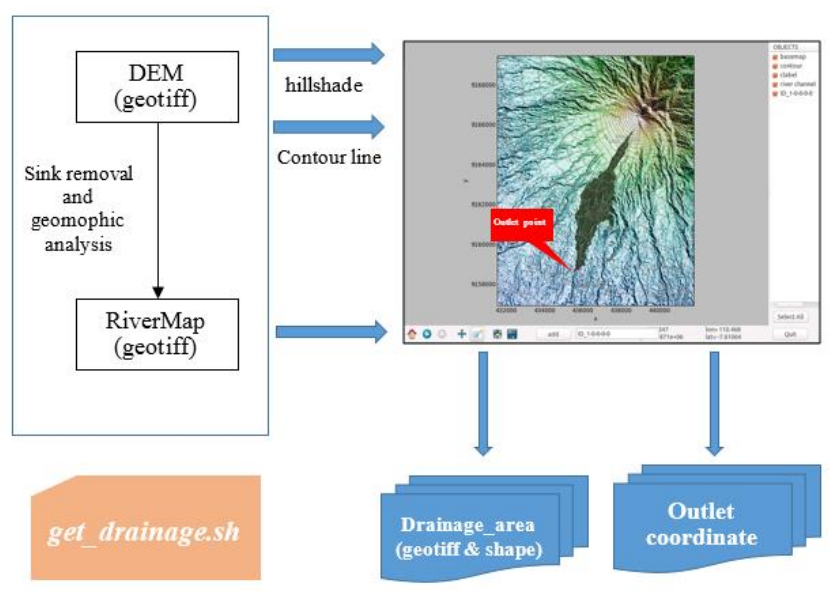

Fig. 7. Concept of getting drainage area.

\subsection{Finding Suitable DEM}

Finding suitable DEM is an important part of the beginning of the analysis of rainfall distribution to support the response of the current stage of drainage area. The available DEM (SRTM1, ASTGTM2, ALOS-AW3D) were differentiated based on the model, temporal coverage and resolution, as shown in Table 3. All of the DEMs are using the same outlet coordinate point that is BO-D5 Boyong Sabo DAM.

Table 3: SRTM1 vs ASTGTM2 vs ALOS3WD

\begin{tabular}{|c|c|c|c|}
\hline Type & Model & Temporal Coverage & Resolution \\
\hline SRTM1 & DEM & $2000-02-11 \sim 2000-02-21$ & $\begin{array}{l}1 \text { arc second } \\
(\text { approx. } 30 \mathrm{~m})\end{array}$ \\
\hline ASTGTM2 & DEM & 2000-01-01 2011-02-28 & $\begin{array}{l}1 \text { arc second } \\
\text { ( approx. } 30 \mathrm{~m})\end{array}$ \\
\hline ALOS-AW3D & DSM & 2006-01 2011-04 & 5 meter \\
\hline World_view (Digital Globe) & DSM & $\begin{array}{l}2011-06 \sim \text { now } \\
\text { (order made) }\end{array}$ & $\begin{array}{l}2 \text { meter } \\
\text { (order made) }\end{array}$ \\
\hline
\end{tabular}

ALOS-AW3D is Digital Surface Model (DSM) type. This kind of DEM is suitable for analysing rainfall distribution due to matching temporal coverage, resolution, and type. ALOSAW3D was divided into two types of resolution, such as $10 \mathrm{~m}$ and $15 \mathrm{~m}$, due to long-duration time processing for getting drainage from the original dem ( $5 \mathrm{~m}$ resolution).

ALOS-AW3D 10m has a void inside the drainage area, which means there is no coverage in that area, so the data are completely non-valid. In this research, ALOS-AW3D 15m, shown in Fig. 8, was chosen for DEM material due to the full coverage of the drainage area. 


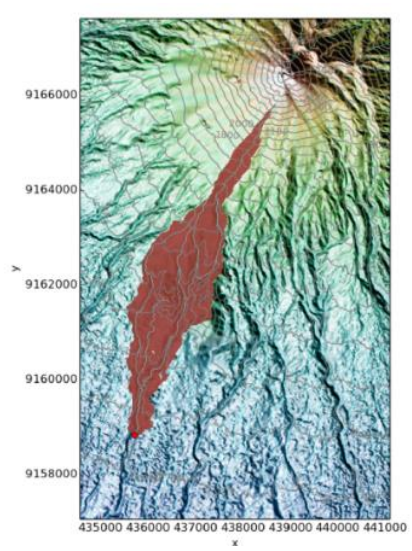

Fig. 8. ALOS3WD with $15 \mathrm{~m}$ resolution.

The result of Boyong drainage area delineation using ALOS-A3WD gives the coordinate of outlet point of Boyong drainage area. The outlet point was assigned at the location of Boyong Sabo DAM with ID name BO - D5 with longitude 110.417 386 and latitude -7.609552.

\subsection{Extracting X-Band MP Rainfall Radar}

After the drainage area is generated, the file that contains the ESRI shapefile is stored in the "drainage result" directory. ESRI shapefile of a set of .shp, .shx, .prj is necessary for extracting rainfall data by identified drainage data. Then overlaying drainage data (GeoTIFF/shapefile) and rainfall data (GeoTIFF). Then, execute using bash command as shown in the concept of extracting X-band rainfall radar in Fig. 9.

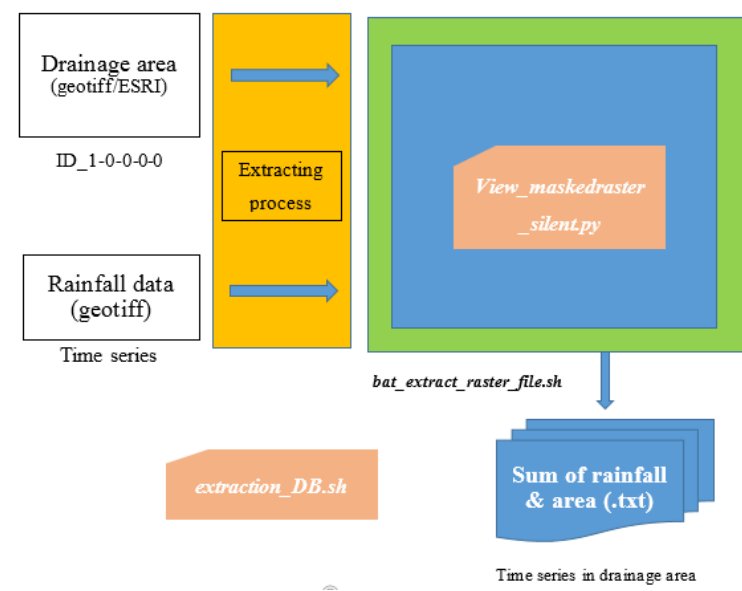

Fig. 9. Concept of extracting X-Band MP rainfall radar with ALOS-3WD 15m resolution.

\subsection{Soil Water Index}

The three-layer tank model program was coded and debugged using a FORTRAN program that supported numerical analysis and scientific computation, structured programming, array programming, high performance computing on supercomputers, and reasonable portability between computer Systems. Fig. 10 is the concept soil water index in the tank model. 


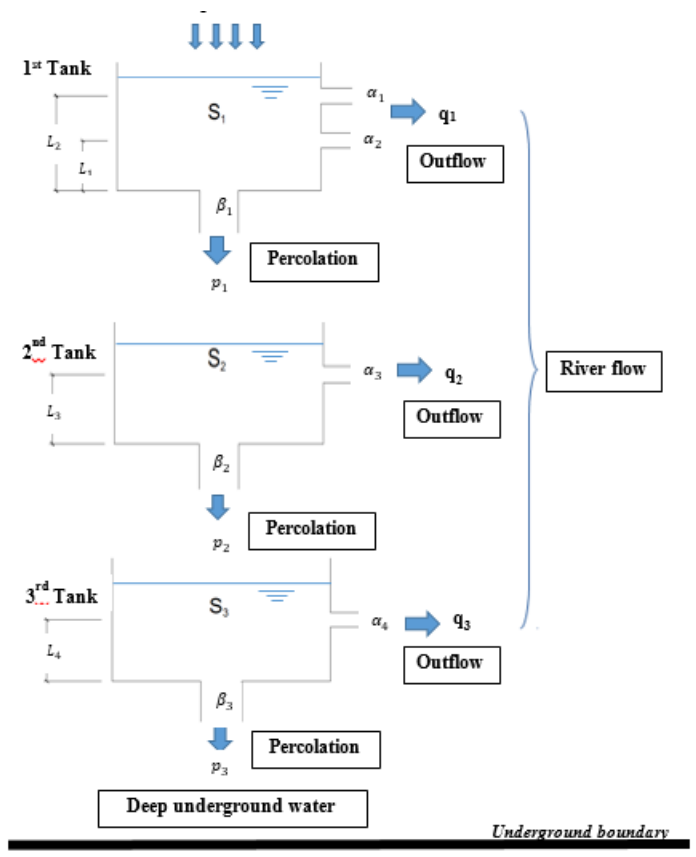

Fig. 10. Concept of Soil Water Index (SWI) in Tank Model.

The time series consists of the sum value of drainage pixel $(\mathrm{mm} / \mathrm{hr})$, mean value of drainage pixels $(\mathrm{mm} / \mathrm{hr})$ and accumulated rainfall $(\mathrm{mm})$. The mean value of drainage pixels corresponds to average rainfall intensity, which is used as rainfall intensity per 2 minutes. The rainfall intensity peak was $53.5102 \mathrm{~mm} /$ hour, occurring on October 20th at 15.20, as shown in the hyetograph in Fig. 11.

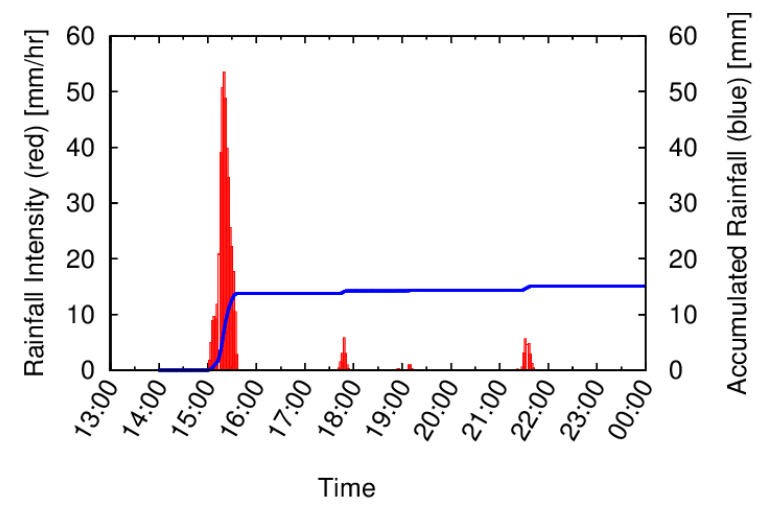

Fig. 11. Hyetograph of rainfall on October $20^{\text {th }} 2018$, in Boyong drainage area (BO-

D5).

Fig. 12 shows the relationship between the time series of rainfall intensity $(\mathrm{mm} / \mathrm{hr})$ and SWI indicates the behaviour of snakeline during October $20^{\text {th }} 2018$. There was an occurrence of rain with the highest intensity within several minutes and the relation with SWI. SWI represents the concept model of soil water content and elucidates soil water content during the rainfall event. As rainfall intensity reaches the highest value, the soil water index will also increase. A higher value of SWI shows a higher risk of sediment disaster initiation. 


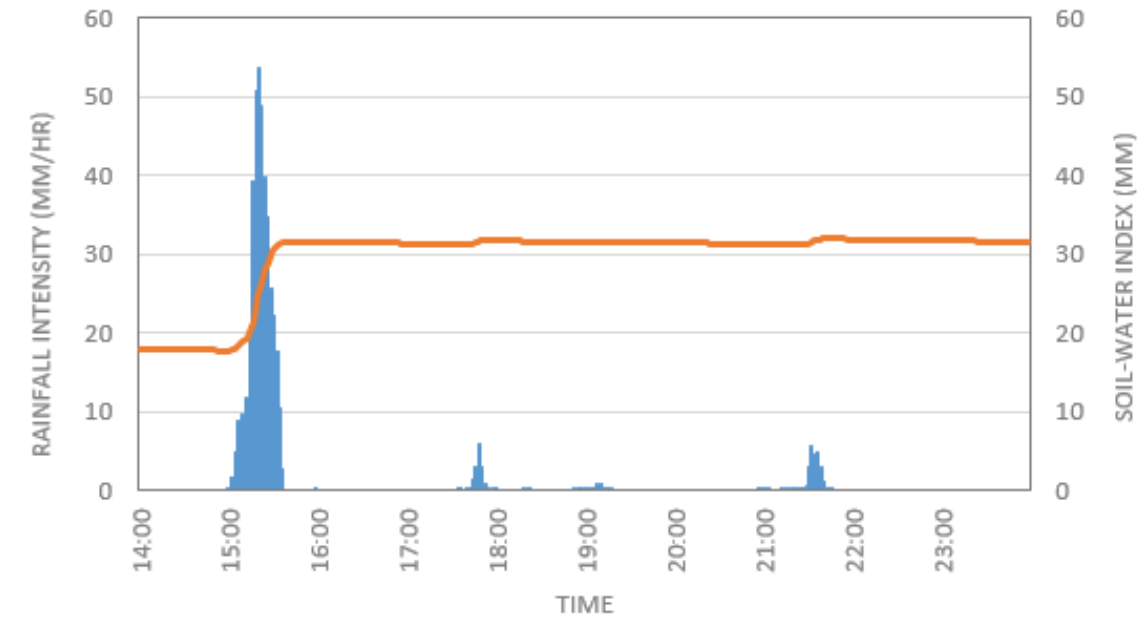

Fig. 12. The relationship of rainfall intensity $(\mathrm{mm} / \mathrm{hr})$ and soil water index $(\mathrm{mm})$ on October $20^{\text {th }} 2018$, as the highest intensity during June 2018 - June 2019.

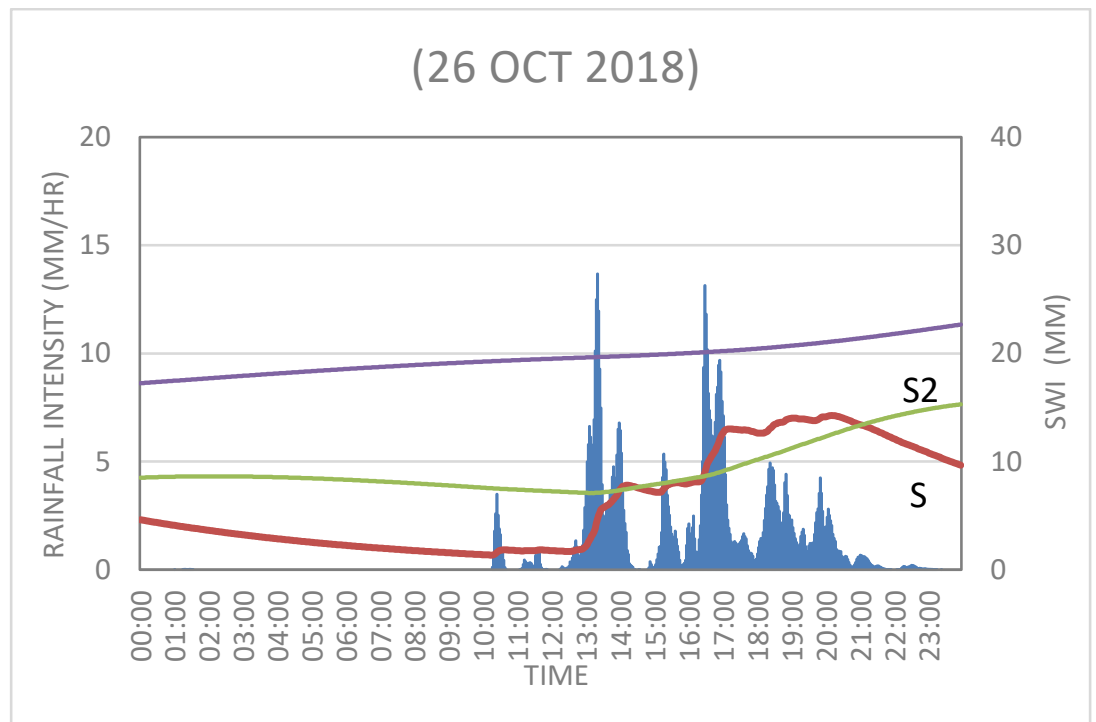

Fig. 13. The relationship of rainfall intensity and water flow (S1, S2, S3) on October $26^{\text {th }} 2018$.

Fig. 13 show that surface flow (S1) has a linear relationship and is responsive to rain due to the first layer that contains direct rainwater. The responsive character of a surface flow is from the behaviour of rainwater inside the tank. When the rain falls to the surface layer, it directly affects the rising of water level in the layer. Sub-surface flow (S2) as the second layer is not too affected on the movement of the surface layer correspond to the smaller coefficient of permeability from the surface layer. The water level in the surface layer depends on the rise of the outflow for surface flow and precipitation process to sub-surface layer then flows out to the surrounding soil. The amount of rainwater in the sub-surface layer is from the precipitation process of the surface layer. Groundwater flow (S3), as the third layer, has a time lag in infiltration due to the small coefficient of permeability from the sub-surface layer. The amount of rainwater in the ground water layer is from the precipitation process of the sub-surface layer.

According to the result, the contribution of rainfall to soil water index (SWI), so the response of water storage from each of three-soil layer (S1, S2 and S3) to rain can be seen. 
This simulation was carried out to show the soil water response to a single rainfall event of 1 $\mathrm{mm} / \mathrm{hr}$.
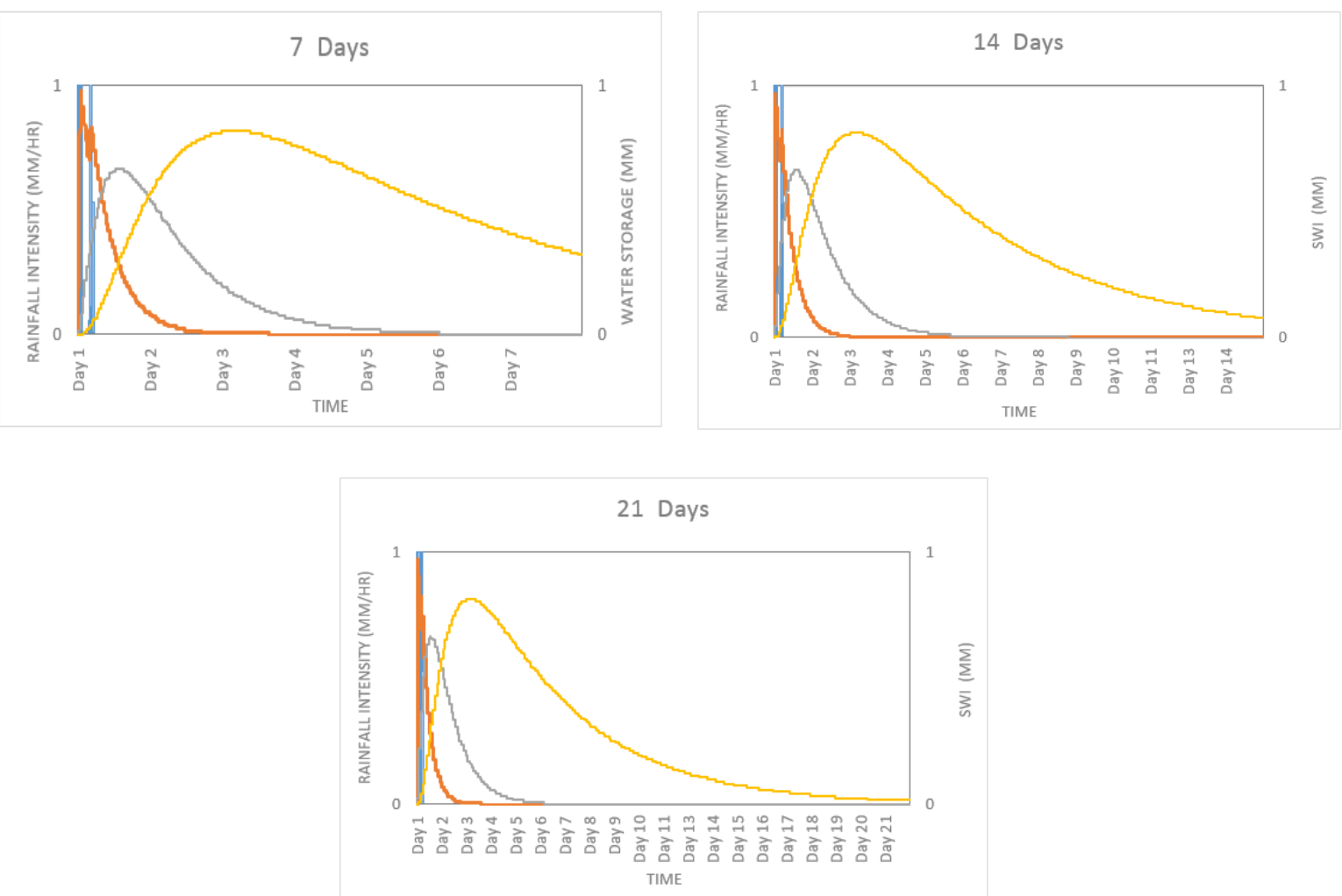

Fig. 14. Hydrograph of water flows in soil layer in 7, 14 and 21 days.

Fig. 14 shows the water storage movement in each three-soil layer (S1, S2, S3). The hydrograph above shows the inclusion of rainwater into the soil layer. The rising limb line shows the responsive line due to rain falling on the soil layer, then reach the peak. After getting the peak, the flow will go down until the approach 0 (zero) value).

Table 4: Changes in the SWI in each month

\begin{tabular}{ccccccc}
\hline No. & $\begin{array}{c}\text { Month- } \\
\text { Year }\end{array}$ & $\begin{array}{c}\text { Rainfall } \\
\text { Intensity max } \\
(\mathbf{m m} / \mathbf{h r})\end{array}$ & $\begin{array}{c}\text { Rainfall } \\
\text { condition }\end{array}$ & $\begin{array}{c}\text { SWI max } \\
(\mathbf{m m})\end{array}$ & $\begin{array}{c}\text { The } \\
\text { rank of } \\
\text { SWI } \\
\text { max }\end{array}$ & $\begin{array}{c}\text { Exceeding SWI } \\
\text { standard value } \\
\mathbf{( 1 2 0}-\mathbf{1 6 0} \mathbf{~ m m})\end{array}$ \\
\hline $\mathbf{1 .}$ & June-18 & 23.18 & LL & 37.92 & 8 & Not exceeding \\
$\mathbf{2 .}$ & July-18 & 47.97 & SH & 27.05 & 11 & Not exceeding \\
$\mathbf{3 .}$ & August-18 & 19.15 & SL & 19.76 & 12 & Not exceeding \\
$\mathbf{4 .}$ & Sept-18 & 30.37 & LH & 32.25 & 10 & Not exceeding \\
$\mathbf{5 .}$ & Oct-18 & 53.51 & LH & 80.28 & 1 & Not exceeding \\
$\mathbf{6 .}$ & Nov-18 & 36.19 & LH & 57.85 & 4 & Not exceeding \\
$\mathbf{7 .}$ & Dec-2018 & 35.13 & LH & 57.83 & 5 & Not exceeding \\
$\mathbf{8 .}$ & Jan-19 & 32.09 & LH & 41.03 & 6 & Not exceeding \\
$\mathbf{9 .}$ & Feb-19 & 41.86 & LH & 67.14 & 3 & Not exceeding \\
$\mathbf{1 0}$ & March-19 & 49.11 & LH & 73.7 & 2 & Not exceeding \\
$\mathbf{1 1 .}$ & April-19 & 33.59 & LH & 38.75 & 7 & Not exceeding \\
$\mathbf{1 2 .}$ & May-19 & 15.79 & SL & 35.7 & 9 & Not exceeding \\
$\mathbf{1 3 .}$ & June-19 & 30.08 & SH & 17.13 & 13 & Not exceeding \\
\hline
\end{tabular}


The changes in SWI and a higher value of SWI shows higher risk closely related to sediment disaster. Fig. 14 shows that although no rainfall occurs, the SWI still shows the value, which gradually decreased due to phenomena of soil water content as influenced by present and antecedent rainfall. The rain then increased the SWI to its maximum value resulting in a mass movement. Based on the result of SWI changes and rainfall conditions were classified into 4 types, short duration-high intensity ( $\mathrm{SH}$ ), short duration-low intensity (SL), long duration-high intensity (LH), long duration-low intensity (LL). According to the result in Fig. 14 , it was assumed that the rainfall $>20 \mathrm{~mm} / \mathrm{hr}$ is categorised as high intensity.

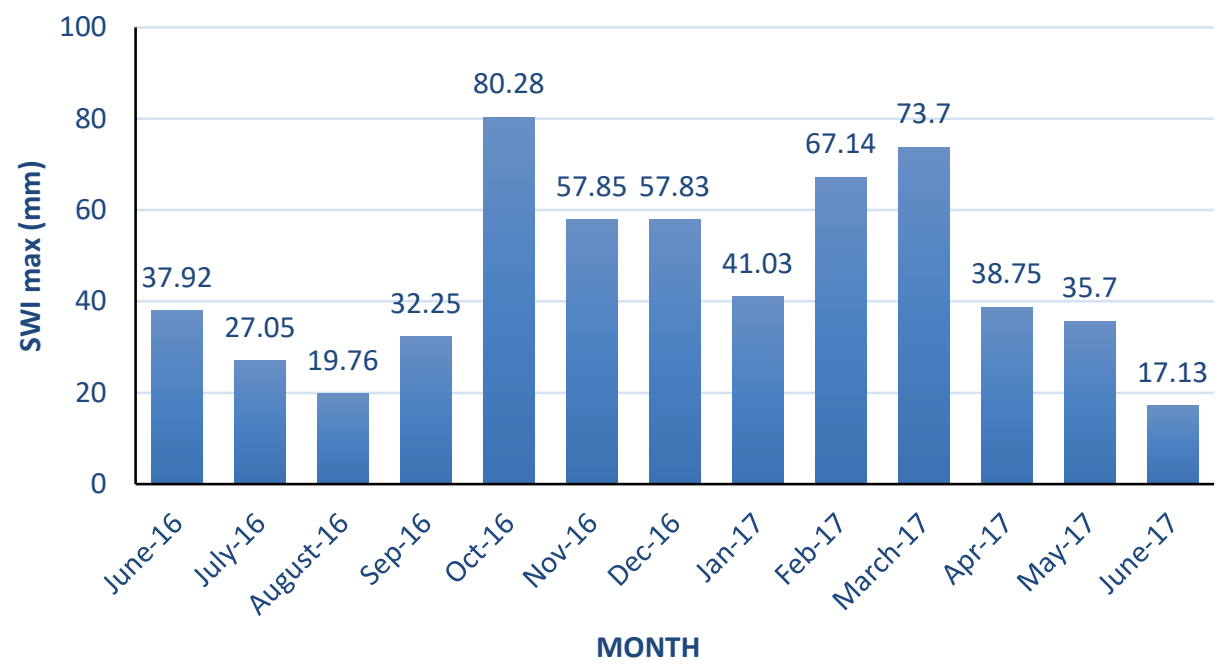

Fig. 15. SWI max changes in Boyong drainage area (June 2018 - June 2019).

From Fig. 15, October 2018 until March 2019, the rapid increase in SWI changes correspond to rainfall conditions tend to be higher and continuously, due to the rainy season, than other months but still not exceeding the standard reference value that JMA set. The research uses criteria set by JMA due to the lack of sediment disaster occurrence data within the dataset range. Of course, the requirements for warning should be selected based on rainfall data recorded as triggering disaster and the occurrence of the disaster itself in the Boyong drainage area. Table 4 shows the long duration-high intensity (LH) events that occur in September 2018 - April 2019. It shows that long duration-high intensity (LH) type is associated with a gradual rise and subsequent constancy of SWI. As rainfall intensity reaches the highest value, the soil water index will also increase. A higher value of SWI shows a higher risk of sediment disaster initiation. A rapid increase in SWI reflects a sporadic intense rainfall, and a rapid increase in SWI combined with high SWI values leads to sediment disaster. Therefore, in such extremely long rainfall events and phenomena of rainfall conditions, continuous and accurate observation of the changes in the SWI is necessary. Since the long duration-high intensity (LH) type greatly influences the SWI changes, this type needs to be paid attention to for sediment disaster prediction. This condition can be used as preliminary consideration for sediment disaster monitoring. The SWI has been used in Japan for nationwide sediment disaster warnings. This research is trying to implement the SWI on snakeline for Boyong river (BOD5) to show the current status of the stage of the response of the Boyong drainage area against rainfall. 


\section{CONCLUSION}

X-band MP (Multi-Parameter) rainfall radar has the benefit to estimate rainfall amounts and precipitation particle size distribution. It effectively establishes precipitation estimation methodology and produces real-time public disclosure of rainfall information using the internet for preliminary sediment disaster prediction. The fluctuation of time series and spatial distribution of rainfall by using X-band MP radar rainfall have produced the rainfall condition phenomena. Based on X-band MP radar rainfall, there was a shift in the rainy season which generally took place starting in November, now shifting forward beginning in October. Using ALOS3WD, which has temporal coverage from 2006-2011, resulted in reading of topographic data that more reflects the current state of Boyong drainage area (BO-D5) in Mt. Merapi.

The soil water content in the Boyong drainage area as represented in the soil water index is used to identify the SWI changes in response between rainfall conditions and recent topography.

The rapid increase in SWI changes from October 2018 until March 2019 corresponds to rainfall conditions tend to be higher and continuously, due to the rainy season, than other months but still not exceeding the standard reference value of SWI $(120-160 \mathrm{~mm})$ JMA set that.

The long duration-high intensity (LH) event occurred from September 2018 until April 2019. It shows that long duration-high intensity (LH) type is associated with a gradual rise and subsequent constancy of SWI and needs attention for sediment disaster prediction. As rainfall intensity reaches the highest value, the soil water index will also increase. A higher value of SWI shows a higher risk of sediment disaster initiation.

\section{ACKNOWLEDGEMENT}

I want to express my special thanks to my professor Kuniaki Moyamoto from Tsukuba University and my lecturers at the Universitas Gadjah Mada. She gave me the golden opportunity to do this wonderful project on the topic which also helped me do a lot of research. I came to know about so many new things. I am thankful to them.

\section{REFERENCES}

[1] N. Osanai, T. Shimizu, K. Kuramoto, S. Kojima, and T. Noro, "Japanese Early-Warning for Debris Flows and Slope Failures Using Rainfall Indices with Radial Basis Function Network," Landslides, vol. 7, no. 3, pp. 325-338, 2010.

[2] C.-W. Chen, H. Saito, and T. Oguchi, "Analysing Rainfall-Induced Mass Movements in Taiwan Using the Soil Water Index," Landslides, vol. 14, no. 3, p. 1031, 2017.

[3] H. R. Destania, "Pengaruh Intensitas Hujan Terhadap Soil Water Index (SWI) Dengan Menggunakan Data Radar," Jurnal Tekno Global, vol. 8, no. 2, 2020.

[4] H. Saito, D. Nakayama, and H. Matsuyama, "Two Types of Rainfall Conditions Associated with Shallow Landslide Initiation in Japan as Revealed by Normalized Soil Water Index," Sola, vol. 6, pp. 57-60, 2010.

[5] H. Saito and H. Matsuyama, "Catastrophic Landslide Disasters Triggered by Record-Breaking Rainfall in Japan: Their Accurate Detection with Normalised Soil Water Index in the Kii Peninsula for the Year 2011," Sola, vol. 8, pp. 81-84, 2012. 